\title{
Percutaneous Closure of Recurrent Post Infarction Ventricular Septal Rupture Following Patch Repair Using A Newly Designed Custom-Made Device
}

\author{
Eustaquio Onorato ${ }^{1}$, Desislava Petrova ${ }^{2}$, and Peter Uzov $^{3}$ \\ ${ }^{1}$ Centro Cardiologico Monzino \\ ${ }^{2}$ Bulgaria Heart and Brain Center, Department of Cardiac Surgery, University Hospital \\ Pleven \\ ${ }^{3}$ Bulgaria Heart and Brain Center
}

July 2, 2020

\begin{abstract}
Here, we describe a successful catheter-based closure of a recurrent post-infarction VSR using a new custom-made device in a 50-year-old man who had previously undergone emergency surgical repair for acute PIVSR with bovine pericardial patch, coronary artery bypass grafting and mitral valve replacement with mechanical prosthesis.
\end{abstract}

\section{Introduction}

Outcomes of conventional and modified surgical infarct exclusion are acceptable in terms of mid-term survival (1). However, despite a successful initial repair, residual VSR can occur in $5 \%$ to $20 \%$ of patients (2-4). Infarct extension may lead to patch dehiscence or create a new rupture beyond the margins of the repaired area (5). In view of the high mortality rate associated with reoperation and given the unstable hemodynamic conditions of the patients, interventional closure may be a less invasive alternative.

\section{Case Report}

A 50 years-old male without cardiovascular risk factors was admitted with acute inferior myocardial infarction for which he underwent percutaneous coronary intervention (PCI) with implantation of two drug-eluting stents, one in the right coronary artery and the other in the obtuse marginal. After the procedure the patient remained hemodynamicaly unstable. His transthoracic echocardiography (TTE) showed left ventricular ejection fraction (LVEF) of 40\%, moderate mitral regurgitation, inferobasal aneurysm and a large muscular VSR in the infero-posterior septum (Figure 1). He was supported with intra-aortic balloon pump and underwent coronary artery bypass graft, bovine pericardial patch VSR closure and mitral valve replacement. Four days later, he was found to have a residual ventricular rupture (Figure 2) which made him symptomatic again. In view of his clinical conditions (NYHA class III), it was decided to address his recurrent VSR using a catheter-based technique. The patient was consented after the local ethics committee and the local regulatory agency have approved the use of the device. The PIVSR was crossed from left to right ventricle using a retrograde arterial approach (left femoral artery) with a $5 \mathrm{~F}$ multipurpose catheter and a Terumo wire that was advanced into the inferior vena cava, where it was snared via the right femoral vein establishing an arteriovenous rail (Figure 3). The $18,6 \mathrm{~mm}$ residual VSR was closed using a newly designed custom-made occluder (PIVSD device, Occlutech® Holding AG, Switzerland) (Suppl Figures 1-3), not CE marked yet, therefore available for compassionate use only. The requesting physician needs to fill and sign a prescription letter, obtain local Ethics Committee approval and get permission from national authorities. 
The waist size of the occluder was $7 \mathrm{~mm}$ larger than the VSR size. The device consists of two self-expanding oval-shaped discs (left $36 \mathrm{~mm}$, right $34 \mathrm{~mm}$ ) composed of a nitinol-wire mesh with "shape-memory" properties joined together by a flexible elliptical waist $10 \mathrm{~mm}$ in length and $24 \mathrm{~mm}$ in diameter. Thin non-woven polyethylene terephthalate (PET) patches are sutured into both discs and into the inside of the waist to ensure rapid sealing of the defect while optimizing ingrowth of tissue. The procedure was performed under general anesthesia with fluoro-angiography and TTE guidance. The occluder was placed at the appropriate site across the rupture and then released. The device was stable and there was a tiny residual shunt immediately after device implantation. The patient made an uneventful recovery and was discharged after 12 days. At dismission TTE confirmed stable position of the device with trivial residual left-to-right shunt (Figure 4). At 12-month follow-up the patient remained symptom free. TTE confirmed stable position of the device with no left-to-right shunt, mild left ventricular dysfunction and normal function of the mitral prosthesis.

\section{DISCUSSION}

Transcatheter closure of PIVSR may provide an attractive and less invasive for residual defects after surgical repair (6). This catheter-based procedure can be accomplished using different devices, some of them not specifically designed for this purpose. To date, the majority of studies of transcatheter closure of postinfarction VSR have reported on the use of Amplatzer muscular VSD occluder and recently on the Amplatzer postinfarction muscular VSD device (PIMVSD) (Abbott Vascular, Santa Clara, CA, USA) (7-12). The Amplatzer PIMVSD device is a nitinol construct available in larger sizes than the Amplatzer muscular VSD device (maximum waist diameter, $24 \mathrm{~mm}$ versus $18 \mathrm{~mm}$, respectively) with a longer connecting waist (10 $\mathrm{mm}$ versus $7 \mathrm{~mm}$ ) and therefore more suited to larger and complex VSRs. Nevertheless, sometimes there's the need to implant additional devices with a substantial increase in procedural risks.

A primary transcatheter closure of an acute anterior post-infarction VSD closure has been performed few

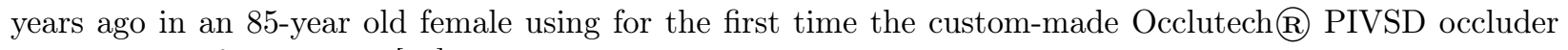
with a successful outcome [13].

The Occlutech ${ }^{\circledR}$ PIVSD occluder is a newly designed device with several advanced features compared to previously existing technology: unique braiding technology, no distal hub, soft and atraumatic flexible ovalshaped discs, special surface treatment reducing the risk of thrombosis. The main advantages of this innovative device in comparison with the Amplatzer post MI occluder are (Suppl Video): first, a wider range of waist sizes (from $16 \mathrm{~mm}$ to $36 \mathrm{~mm}$ ) with bigger left-sided oval disc and a much greater overlap to be able to catch more substantial healthy myocardium and allow a larger surface area between the ventricular septum and the left-sided disc of the device; second, the 10-mm slit-like elliptical connecting waist has no radial strength to prevent tearing the borders of the patch dehiscence; third, due to its conformability, a waist size of the occluder $8 \mathrm{~mm}$ or even $10 \mathrm{~mm}$ larger than the rupture size may be used without undermining the margins of the repaired area.

Polyester fabric sutured into both discs and into the inside of the waist requires time to thrombose and endothelialize before being efficient in preventing shunt across the high transventricular pressure gradient. Further minor device modifications such as a denser fabric and covering on the distal left ventricle disc to completely seal off the shunt ("closure at implant") may be hopefully awaited as well as a dedicated braided and less deformable delivery sheath in order to avoid its kinking.

\section{Conclusions}

Percutaneous closure of recurrent PIVSR following patch repair is feasible and may be considered the first-line treatment option.

Keys for success are a good clinical pre-procedural management, the availability of an innovative device and an excellent teamwork.

\section{Acknowledgments}

The authors express their appreciation to the staff at Bulmar ML Ltd., Bulgaria for their logistic support. 
The authors also thank the engineering and marketing staff at Occlutech for technical descriptions of the device and for illustrations.

Conflict of Interes t: Eustaquio Maria Onorato is a consultant for Occlutech, manufacturer of the device. The remaining Authors declare no confict of interest relevant to this publication.

ORCID : Eustaquio Maria Onorato https://orcid.org/0002-6750-5682p

Author Contribution : The Authors have contributed significantly to the submitted work, in the conception, design and interpretation of data, drafting of the manuscript and final approval of the manuscript submitted.

\section{References}

1. Topaz O, Taylor AL. Interventricular septal rupture complicating acute myocardial infarction: from pathophysiologic features to the role of invasive and noninvasive diagnostic modalities in current management. Am J Med 1992;93:683-8.

2. Antman EM, Hand M, Armstrong PW et al. 2007 Writing Group to Review New Evidence and Update the ACC/AHA 2004 Guidelines for the Management of Patients with ST-Elevation Myocardial Infarction, Writing on Behalf of the 2004 Writing Committee. Circulation 2008;117:296-329.

3. Okamoto Y, Yamamoto K, Asami F et al. Early and midterm outcomes of triple patch technique for postinfarction ventricular septal defects. Thorac Cardiovasc Surg 2016;151:1711-1716.

4. Sayfo S, Stepp LO, Ganzel B et al. Management of Recurrent Leaks Following Postinfarction Ventricular Septal Defect Repairs. J Card Surg 2012;27:576-580

5. Shah NV, BA, Goldstein JA, Balzer DT et al. Transcatheter Repair of Recurrent Postinfarct Ventricular Septal Defects. Ann Thorac Surg 2005;80:1907-1909.

6. Tang L, Fang Z, Hu X, Tang J, Shen X, Lu X et al. Non-surgical repair of ventricular septal rupture after acute myocardial infarction. Int J Cardiol. 2015;185:328-332.

7. Costache VS, Chavanon O, Bouvaist H et al. Early Amplatzer occluder closure of a postinfarct ventricular septal defect as a bridge to surgical procedure. Interact Cardiovasc Thorac Surg. 2007;6:503-504.

8. Calvert PA, Cockburn J, Wynne D et al. Percutaneous closure of postinfarction ventricular septal defect: in-hospital outcomes and long-term follow-up of UK experience. Circulation 2014;129:23952402 .

9. Shabestari M, Ghaderi F, Hamedanchi A. Transcatheter Closure of Postinfarction Ventricular Septal Defect: A Case Report and Review of Literature. J Cardiovasc Thorac Res, 2015;7:75-77.

10. Barik R. Transcatheter closure of post-myocardial infarction ventricular defect: where are we? Indian Heart Journal 2016;68:99-101.

11. Sabiniewicz R, Huczek Z, Zbroński K et al. Percutaneous Closure of Post-Infarction Ventricular Septal Defects - An Over Decade-long Experience. J Interv Cardiol 2017;30:63-71.

12. Holzer R, Balzer D, Amin Z et al. Transcatheter closure of postinfarction ventricular septal defects using the new Amplatzer muscular VSD occluder: Results of a U.S. Registry. Catheter Cardiovasc Interv 2004;61:196-201.

13. Fitzsimmons SJ, Macdonald S, Richens T, Vettukattil J. Transcatheter closure of an inferior post infarction ventricular septal defect using a customised device. Eur Heart J 2013;34(1):P4349.

\section{Figures legends}

Figure 1 . Two-dimensional transesophageal echocardiography (TEE) image showing a large ventricular septal rupture $28 \mathrm{~mm}$ in diameter (bracket) located at the infero-posterior septum.

$\mathrm{RV}$ : right ventricle; LV: left ventricle; LA: left atrium

Figure 2 . Two-dimensional transthoracic echocardiography (TTE) apical four-chamber (A,B ) and shortaxis color Doppler (C,D ) views showing post-surgical ventricular residual rupture 18,6 $\mathrm{mm}$ in diameter (yellow arrow) with left-to-right shunt (white arrow). 
RV: right ventricle; LV: left ventricle

Figure 3 . Fluoro-angiographic steps of the interventional procedure. A : An arteriovenous rail established using a retrograde arterial approach (left femoral artery) with a $5 \mathrm{~F}$ multipurpose catheter and a Terumo wire that was advanced through the septal rupture into the inferior vena cava, where it was snared via the right femoral vein; B-D : the $24 \mathrm{~mm}$ PIVSR occluder (black arrows) delivered through the dedicated delivery system (arrowhead) across the septal rupture; the welded ball of the device is secured to the dedicated delivery system (white arrow); $\mathbf{E}$ : zoom fluoro image showing the device deployment: the welded ball (white long arrow) is no more attached to the dedicated Flex Pusher II delivery system; two radiopaque gold markers are clearly seen on the distal disc. F : final LV angiogram showing a stable device position with mild residual left-to-right shunt.

Figure 4 . Two-dimensional transthoracic echocardiography (TTE) at 6-month follow-up. Apical fourchamber (A ) and short-axis color Doppler (B-C) views showing the $24 \mathrm{~mm}$ PIVSD occluder in situ (yellow arrow) with trivial residual left-to-right shunt.

RV: right ventricle; LV: left ventricle

\section{Supplementary Material}

Supplemetal Figure 1. Post-Myocardial Infarction Ventricular Septal Defect (PIVSD) Device (Occlutech Holding AG, Switzerland). Available sizes, corresponding to the length of the waist major axis, vary from 16 $\mathrm{mm}$ to $36 \mathrm{~mm}$ as well as disc diameters (from 28/26 $\mathrm{mm}$ to $49 / 44 \mathrm{~mm}$ ). Proximal disc diameters are smaller than distal disc ones. The connecting elliptical waist length (h) is $10 \mathrm{~mm}$ for all device's sizes. The dedicated delivery system (Flex II Pusher and Pistol Pusher) sizes range from 9 to 14F.

Supplemetal Figure 2 . The Occlutech PIVSD occluder consists of two self-expanding rounded discs joined together by a 10-mm flexible elliptical waist. The discs and the elliptical waist are composed of a nitinol-wire mesh with "shape-memory" properties. Thin non-woven polyethylene terephthalate patches are sutured into both discs and inside the waist to ensure rapid sealing of the defect while optimizing ingrowth of tissue. Two radiopaque gold markers located on the distal disc are intended to facilitate proper positioning of the device. The size of the device corresponds to the length of the waist major axis (orange line, b: side view). Waist length (h) is $10 \mathrm{~mm}$ for all device's sizes. The welded ball is located on the proximal disc (with permission of Occlutech (R) Holding AG, Switzerland).

Supplemental Figure 3. On the proximal side of the occluder, the wire braiding ends in a welded ball that serves as an adapter (ball-connector) for the dedicated delivery system (Flex-Pusher II).

\section{Supplemental Video}

https://occlutech.box.com/s/bqarmlogfb3tr4ermn7789lvt0v0nni4 


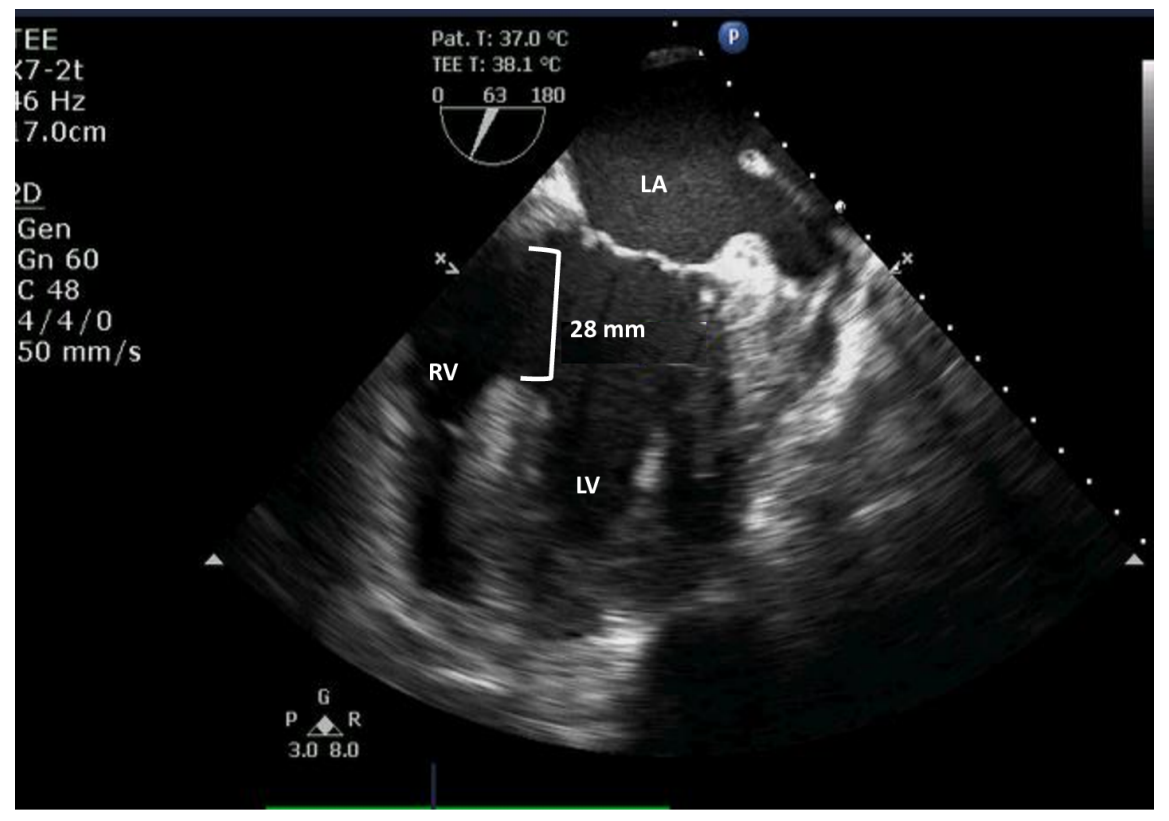

Figure 1.

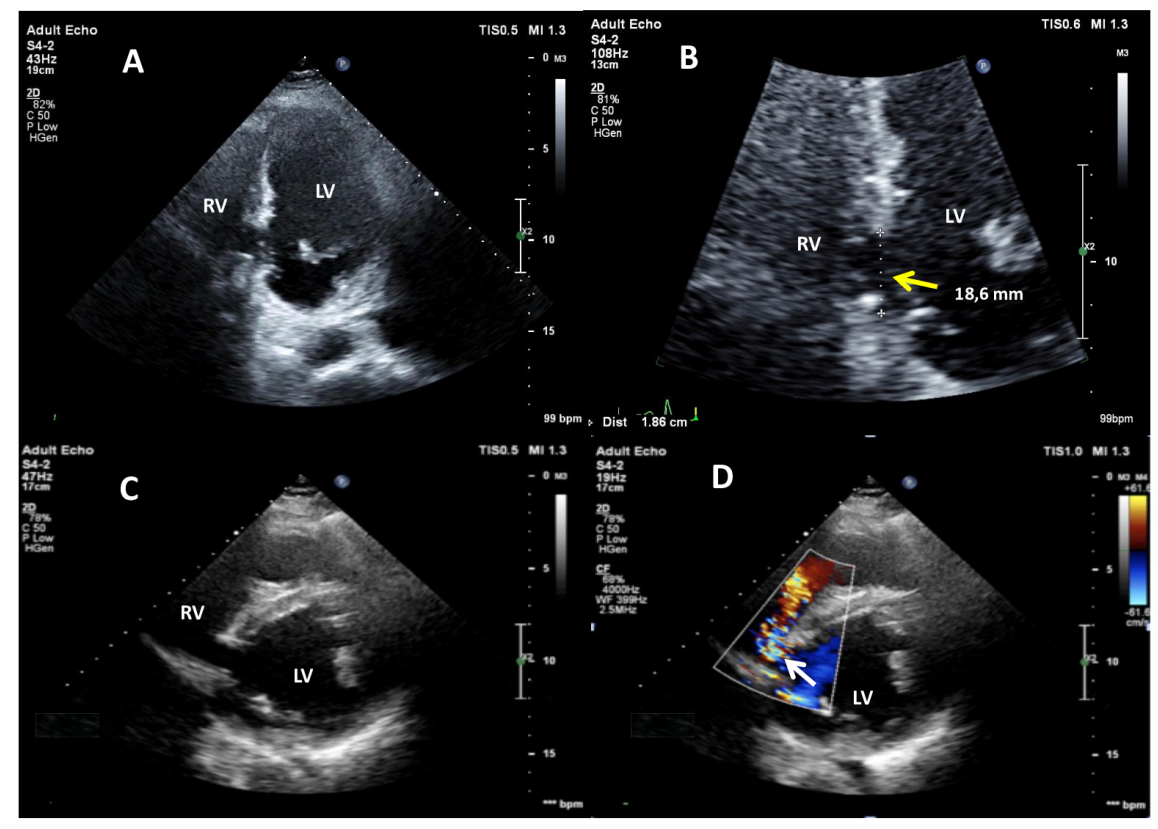

Figure 2. 


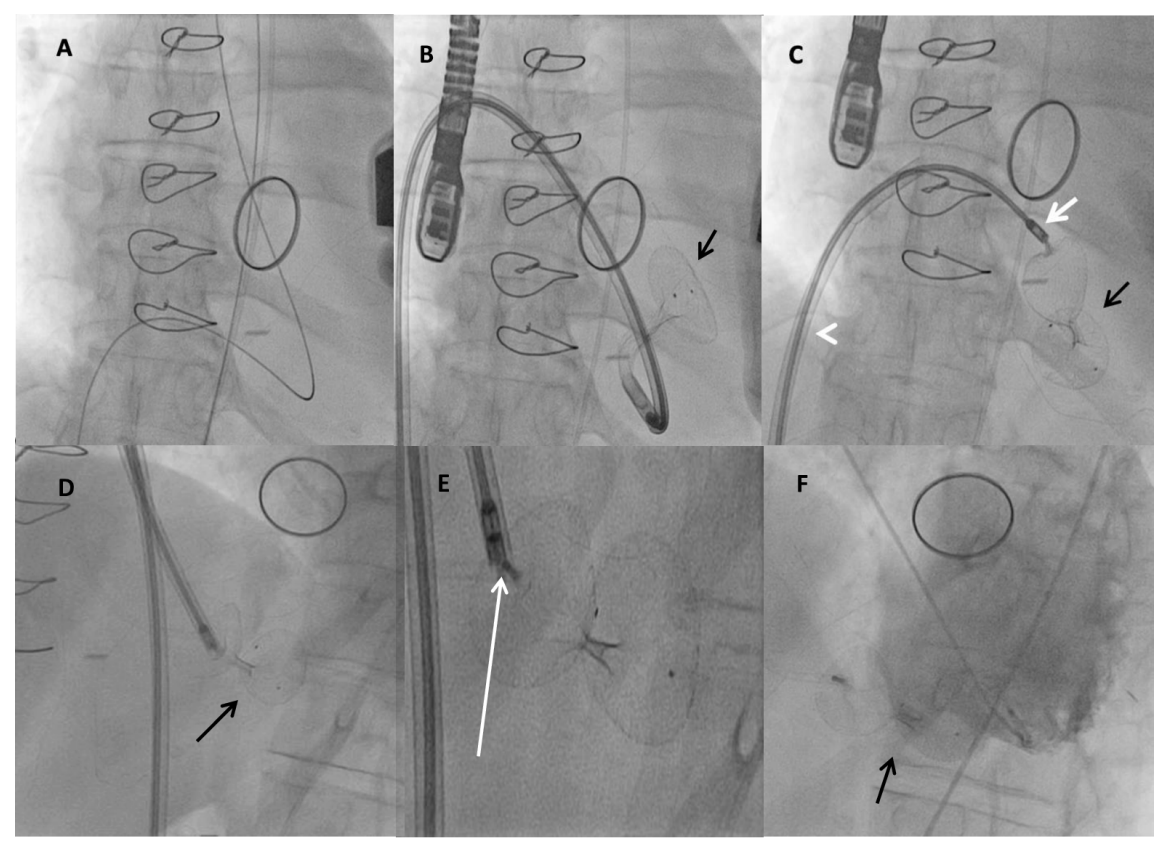

Figure 3.

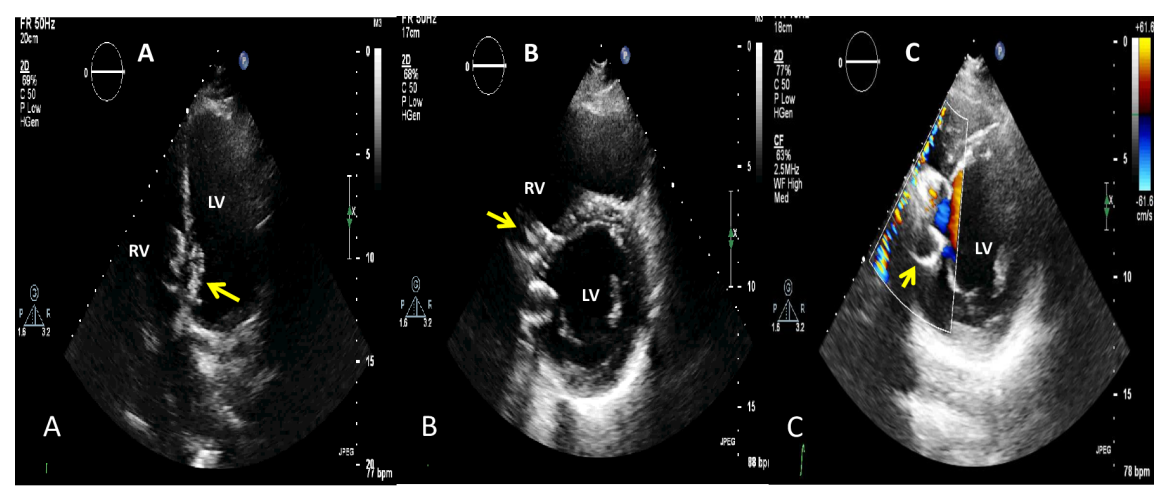

Figure 4. 

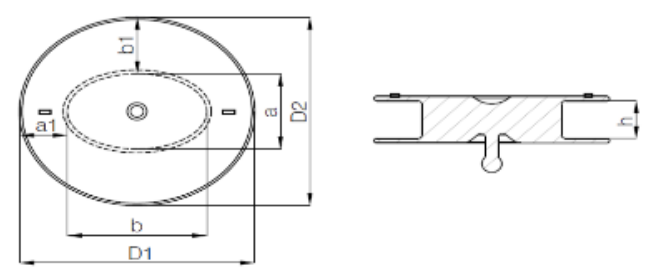

D1: Major Disc Diameter, D2: Minor Disc Diameter, a: Minor Waist Diameter, b: Major Waist Diameter. a1: Minor Disc Rim Length, b1: Major Disc Rim Length, h: Waist Length

\begin{tabular}{|c|c|c|c|c|c|c|c|c|c|c|}
\hline \multirow{2}{*}{$\begin{array}{l}\text { Article } \\
\text { Number }\end{array}$} & \multirow{2}{*}{$\underset{[m m}{a}$} & \multirow{2}{*}{$\begin{array}{c}\text { a1 } \\
\text { [mm] }\end{array}$} & \multirow{2}{*}{$\underset{\text { [mm] }}{\mathbf{b}}$} & \multirow{2}{*}{$\begin{array}{c}\text { b1 } \\
{[\mathrm{mm}]}\end{array}$} & \multirow{2}{*}{$\begin{array}{c}\mathbf{h} \\
{[\mathrm{mm}]}\end{array}$} & \multirow{2}{*}{$\begin{array}{c}\text { D1 } \\
{[\mathbf{m m}]}\end{array}$} & \multirow{2}{*}{$\underset{[\mathrm{mm}]}{\mathrm{D2}}$} & \multirow{2}{*}{$\begin{array}{l}\text { Oooluteoh } \\
\text { Delivery } \\
\text { System } \\
\text { (ODS) Size }\end{array}$} & \multicolumn{2}{|c|}{ Pusher System Item } \\
\hline & & & & & & & & & $\begin{array}{l}\text { Pistol } \\
\text { Pusher } \\
\text { Item No }\end{array}$ & $\begin{array}{c}\text { Flex II } \\
\text { Pusher } \\
\text { Item No }\end{array}$ \\
\hline 70 VSD 16 & 10 & 5,65 & 16 & 7 & 10 & 28 & 26 & $9 F$ & $\begin{array}{l}\text { 55PP 165 } \\
\text { Yellow }\end{array}$ & $\begin{array}{l}\text { 51FP120 } \\
\text { Yellow }\end{array}$ \\
\hline 70 VSD 20 & 10 & 5,65 & 20 & 9 & 10 & 32 & 30 & $10 F$ & $\begin{array}{l}\text { 55PP165 } \\
\text { Yellow }\end{array}$ & $\begin{array}{l}51 \text { FP120 } \\
\text { Yellow }\end{array}$ \\
\hline 70 VSD 24 & 10 & 5,65 & 24 & 11 & 10 & 36 & 34 & $12 \mathrm{~F}$ & $\begin{array}{l}\text { 55PP } 185 \\
\text { Violet }\end{array}$ & $\begin{array}{l}\text { 51FP150 } \\
\text { Violet }\end{array}$ \\
\hline 70 VSD 28 & 10 & 6,5 & 28 & 13 & 12 & 41 & 38 & $14 \mathrm{~F}$ & $\begin{array}{l}\text { 55PP210 } \\
\text { Dark Blue }\end{array}$ & $\begin{array}{l}\text { 51FP160 } \\
\text { Dark Blue }\end{array}$ \\
\hline 70 VSD 32 & 10 & 6,5 & 32 & 15 & 12 & 45 & 42 & $14 \mathrm{~F}$ & $\begin{array}{l}\text { 55PP210 } \\
\text { Dark Blue }\end{array}$ & $\begin{array}{l}\text { 51FP160 } \\
\text { Dark Blue }\end{array}$ \\
\hline 70 VSD 36 & 10 & 6.5 & 36 & 16.5 & 12 & 49 & 44 & $14 \mathrm{~F}$ & $\begin{array}{l}\text { 55PP210 } \\
\text { Dark Blue }\end{array}$ & $\begin{array}{l}\text { 51FP160 } \\
\text { Dark Blue }\end{array}$ \\
\hline
\end{tabular}

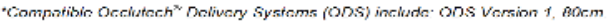

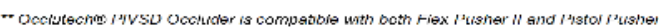

\section{Supplemental Figure 1.}
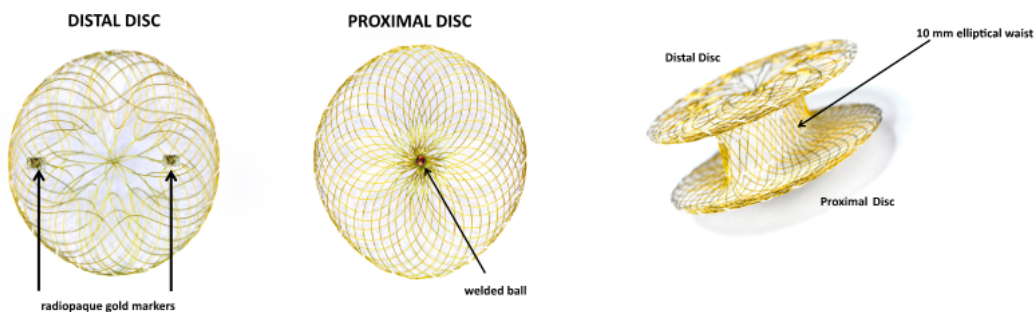

Distal Dise
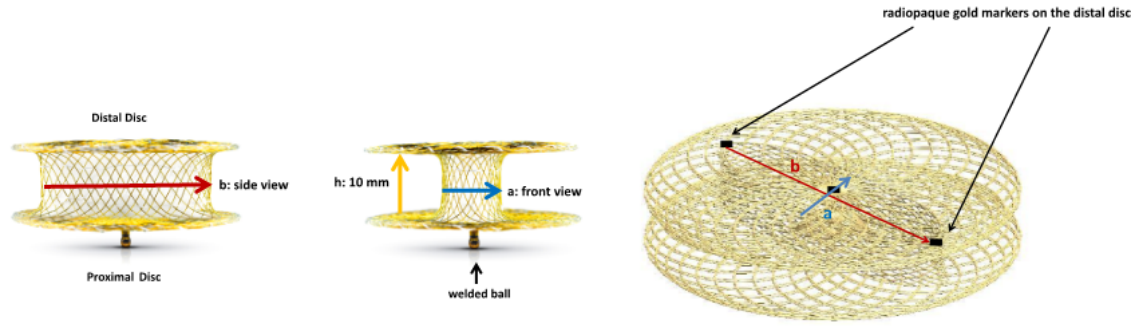

Supplemental Figure 2. 


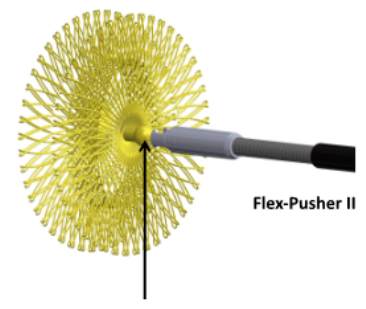

Welded ball

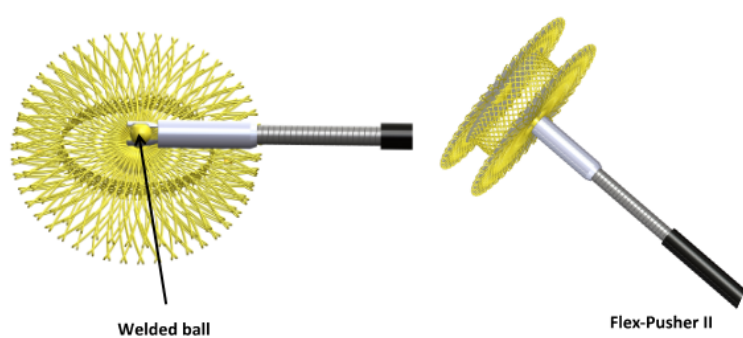

Supplemental Figure 3. 